\title{
THE EQUIVALENCE BETWEEN THE MANN AND \\ ISHIKAWA ITERATIONS DEALING WITH \\ GENERALIZED CONTRACTIONS
}

B. E. RHOADES AND ŞTEFAN M. ŞOLTUZ

Received 25 January 2006; Revised 10 May 2006; Accepted 11 May 2006

We show that the Mann and Ishikawa iterations are equivalently used to approximate fixed points of generalized contractions.

Copyright (c) 2006 Hindawi Publishing Corporation. All rights reserved.

\section{Introduction}

Let $X$ be a real Banach space, $A$ a nonempty convex subset of $X, T$ a selfmap of $A$, and let $x_{0}=u_{0} \in A$. The Mann iteration (see [2]) is defined by

$$
u_{n+1}=\left(1-\alpha_{n}\right) u_{n}+\alpha_{n} T u_{n} .
$$

The Ishikawa iteration is defined (see [1]) by

$$
\begin{gathered}
x_{n+1}=\left(1-\alpha_{n}\right) x_{n}+\alpha_{n} T y_{n}, \\
y_{n}=\left(1-\beta_{n}\right) x_{n}+\beta_{n} T x_{n},
\end{gathered}
$$

where $\left\{\alpha_{n}\right\} \subset(0,1),\left\{\beta_{n}\right\} \subset[0,1)$.

These methods were applied, in [3], to a class of functions $T$ satisfying the inequality

$$
\|T x-T y\| \leq Q(M(x, y)),
$$

where $Q$ is a real-valued function satisfying

(a) $0<Q(s)<s$ for each $s>0$ and $Q(0)=0$,

(b) $Q$ is nondecreasing on $(0, \infty)$,

(c) $g(s):=s /(s-Q(s))$ is nonincreasing on $(0, \infty)$,

$$
M(x, y):=\max \{\|x-y\|,\|x-T x\|,\|y-T y\|,\|x-T y\|,\|y-T x\|\} .
$$

In [4], the following conjecture was given: "if the Mann iteration converges, then so does the Ishikawa iteration.” In a series of papers [4-8], the authors have given a positive answer to this conjecture, showing, for example, the equivalence between Mann and 
Ishikawa iterations for strongly and uniformly pseudocontractive maps. In this note, we show that the convergence of Mann iteration is equivalent to the convergence of Ishikawa iteration, used to approximate fixed points of a map which satisfies condition (1.3). Such a map is independent of the class of strongly pseudocontractive maps. The class of generalized contractions satisfying (1.3) generalizes the class of quasi-contractions, see, for example, [9]. Thus, our result generalizes the main [9, Theorem 1], which states the equivalence between Mann and Ishikawa iterations when applied to quasi-contractions.

LEMmA 1.1 [10]. Let $\left\{a_{n}\right\}$ be a nonnegative sequence which satisfies the following inequality:

$$
a_{n+1} \leq\left(1-\lambda_{n}\right) a_{n}+\sigma_{n}
$$

where $\lambda_{n} \in(0,1)$ for all $n \geq n_{0}, \sum_{n=1}^{\infty} \lambda_{n}=\infty$, and $\sigma_{n}=o\left(\lambda_{n}\right)$. Then $\lim _{n \rightarrow \infty} a_{n}=0$.

The following result is a lemma from [3, page 351].

Lemma 1.2 [3]. Let $A$ be a nonempty closed convex subset of a Banach space $X$, and $T$ a self-map of $A$ satisfying (1.3). Let $\left\{\alpha_{n}\right\}$ satisfy the conditions $\alpha_{n}>0$ for all $n \geq 0$ and $\sum_{n=0}^{\infty} \alpha_{n}=\infty$. Then the sequences $\left\{x_{n}\right\},\left\{y_{n}\right\},\left\{u_{n}\right\},\left\{T x_{n}\right\},\left\{T y_{n}\right\}$, and $\left\{T u_{n}\right\}$ are bounded.

\section{Main result}

Theorem 2.1. Let $A$ be a nonempty closed convex subset of a Banach space $X$, and $T$ a self-map of $A$ satisfying (1.3). Let $\left\{\alpha_{n}\right\}$ satisfy the conditions $\alpha_{n}>0$ for all $n \geq 0$ and $\sum_{n=0}^{\infty} \alpha_{n}=\infty$. Denote by $x^{*}$ the unique fixed point of $T$. Then for $u_{0}=x_{0} \in A$, the following are equivalent:

(i) the Mann iteration (1.1) converges to $x^{*}$;

(ii) the Ishikawa iteration (1.2) converges to $x^{*}$.

Proof. Lemma 1.2 assures that both Mann and Ishikawa iterations are bounded and hence, in order to prove the equivalence between (1.1) and (1.2), we need to prove that

$$
\lim _{n \rightarrow \infty}\left\|x_{n}-u_{n}\right\|=0 .
$$

Set

$$
\begin{aligned}
& r_{n}=\max \{ \sup \left(\left\|x_{n}-T y_{j}\right\|: j \geq n\right) \cup \sup \left(\left\|u_{n}-T u_{j}\right\|: j \geq n\right) \\
&\left.\cup \sup \left(\left\|x_{n}-T u_{j}\right\|: j \geq n\right) \cup \sup \left(\left\|u_{n}-T y_{j}\right\|: j \geq n\right)\right\} .
\end{aligned}
$$

Then the following are true:

$$
\begin{aligned}
\left\|x_{n}-T y_{j}\right\| & \leq\left(1-\alpha_{n-1}\right)\left\|x_{n-1}-T y_{j}\right\|+\alpha_{n-1}\left\|T y_{n-1}-T y_{j}\right\| \\
& \leq\left(1-\alpha_{n-1}\right) r_{n-1}+\alpha_{n-1} Q\left(M\left(y_{n-1}, y_{j}\right)\right) \\
& \leq\left(1-\alpha_{n-1}\right) r_{n-1}+\alpha_{n-1} Q\left(r_{n-1}\right), \\
\left\|u_{n}-T u_{j}\right\| & \leq\left(1-\alpha_{n-1}\right)\left\|u_{n-1}-T u_{j}\right\|+\alpha_{n-1}\left\|T u_{n-1}-T u_{j}\right\| \\
& \leq\left(1-\alpha_{n-1}\right) r_{n-1}+\alpha_{n-1} Q\left(M\left(u_{n-1}, u_{j}\right)\right) \\
& \leq\left(1-\alpha_{n-1}\right) r_{n-1}+\alpha_{n-1} Q\left(r_{n-1}\right),
\end{aligned}
$$


moreover,

$$
\begin{aligned}
\left\|x_{n}-T u_{j}\right\| & \leq\left(1-\alpha_{n-1}\right)\left\|x_{n-1}-T u_{j}\right\|+\alpha_{n-1}\left\|T y_{n-1}-T u_{j}\right\| \\
& \leq\left(1-\alpha_{n-1}\right) r_{n-1}+\alpha_{n-1} Q\left(M\left(y_{n-1}, u_{j}\right)\right) \\
& \leq\left(1-\alpha_{n-1}\right) r_{n-1}+\alpha_{n-1} Q\left(r_{n-1}\right),
\end{aligned}
$$

also,

$$
\begin{aligned}
\left\|u_{n}-T y_{j}\right\| & \leq\left(1-\alpha_{n-1}\right)\left\|u_{n-1}-T y_{j}\right\|+\alpha_{n-1}\left\|T u_{n-1}-T y_{j}\right\| \\
& \leq\left(1-\alpha_{n-1}\right) r_{n-1}+\alpha_{n-1} Q\left(M\left(u_{n-1}, y_{j}\right)\right) \\
& \leq\left(1-\alpha_{n-1}\right) r_{n-1}+\alpha_{n-1} Q\left(r_{n-1}\right) .
\end{aligned}
$$

Eventually, one gets the following evaluation:

$$
r_{n} \leq\left(1-\alpha_{n-1}\right) r_{n-1}+\alpha_{n-1} Q\left(r_{n-1}\right) \Longleftrightarrow \alpha_{n-1} g\left(r_{n-1}\right) \leq r_{n-1}-r_{n},
$$

which implies that $\left\{r_{n}\right\}$ is nonincreasing in $n$ and positive. Hence, there exists $\lim _{n \rightarrow \infty} r_{n}$, denoted by $r \geq 0$. Suppose $r>0$. From (2.6), we obtain

$$
\alpha_{n-1} g(r) \leq \alpha_{n-1} g\left(r_{n-1}\right) \leq r_{n-1}-r_{n} \Longleftrightarrow g(r) \sum_{k=0}^{n} \alpha_{k} \leq \sum_{k=0}^{n}\left(r_{k}-r_{k-1}\right)=r_{0}-r_{n+1} .
$$

The right-hand side is bounded and the left-hand side is unbounded. Thus, $r=0$. Hence,

$$
\begin{array}{ll}
\lim _{n \rightarrow \infty}\left\|x_{n}-T u_{n}\right\|=0, & \lim _{n \rightarrow \infty}\left\|u_{n}-T y_{n}\right\|=0, \\
\lim _{n \rightarrow \infty}\left\|x_{n}-T y_{n}\right\|=0, & \lim _{n \rightarrow \infty}\left\|u_{n}-T u_{n}\right\|=0 .
\end{array}
$$

Suppose now that the Mann iteration converges, then one has

$$
\begin{aligned}
\left\|x_{n+1}-u_{n+1}\right\| & \leq\left(1-\alpha_{n}\right)|| x_{n}-u_{n}\left\|+\alpha_{n}\right\| T y_{n}-T u_{n} \| \\
& \leq\left(1-\alpha_{n}\right)\left\|x_{n}-u_{n}\right\|+\alpha_{n}\left(|| T y_{n}-x_{n}\|+\| x_{n}-T u_{n} \|\right) .
\end{aligned}
$$

Using (2.8) and (2.9) and Lemma 1.1, with

$$
\begin{gathered}
\lambda_{n}:=\left\|x_{n}-u_{n}\right\|, \\
\sigma_{n}:=\alpha_{n}\left(\left\|T y_{n}-x_{n}\right\|+\left\|x_{n}-T u_{n}\right\|\right), \\
\sigma_{n}=o\left(\alpha_{n}\right),
\end{gathered}
$$




\section{Equivalent iterations for generalized contractions}

we have $\lim _{n \rightarrow \infty} \lambda_{n}=0$, that is, (2.1) holds. The relation

$$
\left\|x_{n}-x^{*}\right\| \leq\left\|x_{n}-u_{n}\right\|+\left\|x^{*}-u_{n}\right\| \longrightarrow 0
$$

leads to the conclusion that Ishikawa iteration converges too. Suppose now that the Ishikawa iteration converges, then one has

$$
\begin{aligned}
\left\|x_{n+1}-u_{n+1}\right\| & \leq\left(1-\alpha_{n}\right)\left\|x_{n}-u_{n}\right\|+\alpha_{n}\left\|T y_{n}-T u_{n}\right\| \\
& \leq\left(1-\alpha_{n}\right)\left\|x_{n}-u_{n}\right\|+\alpha_{n}\left(\left\|T y_{n}-u_{n}\right\|+\left\|u_{n}-T u_{n}\right\|\right)
\end{aligned}
$$

Using (2.8) and (2.12) and Lemma 1.1, with

$$
\begin{gathered}
\lambda_{n}:=\left\|x_{n}-u_{n}\right\|, \\
\sigma_{n}:=\alpha_{n}\left(\left\|T y_{n}-u_{n}\right\|+\left\|u_{n}-T u_{n}\right\|\right), \\
\sigma_{n}=o\left(\alpha_{n}\right),
\end{gathered}
$$

we have $\lim _{n \rightarrow \infty} \lambda_{n}=0$, that is, (2.1) holds. The relation

$$
\left\|u_{n}-x^{*}\right\| \leq\left\|x_{n}-u_{n}\right\|+\left\|x_{n}-x^{*}\right\| \longrightarrow 0
$$

leads to the conclusion that Mann iteration converges too.

\section{Acknowledgment}

The authors are indebted to the referees for carefully reading this note and for making useful suggestions.

\section{References}

[1] S. Ishikawa, Fixed points by a new iteration method, Proceedings of the American Mathematical Society 44 (1974), no. 1, 147-150.

[2] W. R. Mann, Mean value methods in iteration, Proceedings of the American Mathematical Society 4 (1953), no. 3, 506-510.

[3] B. E. Rhoades, Convergence of an Ishikawa-type iteration scheme for a generalized contraction, Journal of Mathematical Analysis and Applications 185 (1994), no. 2, 350-355.

[4] B. E. Rhoades and Ş. M. Şoltuz, On the equivalence of Mann and Ishikawa iteration methods, International Journal of Mathematics and Mathematical Sciences 2003 (2003), no. 7, 451-459.

[5] __ The equivalence between the convergences of Ishikawa and Mann iterations for an asymptotically pseudocontractive map, Journal of Mathematical Analysis and Applications 283 (2003), no. 2, 681-688.

[6] _ . The equivalence of Mann iteration and Ishikawa iteration for non-Lipschitzian operators, International Journal of Mathematics and Mathematical Sciences 2003 (2003), no. 42, 26452651.

[7] ___ The equivalence between the convergences of Ishikawa and Mann iterations for an asymptotically nonexpansive in the intermediate sense and strongly successively pseudocontractive maps, Journal of Mathematical Analysis and Applications 289 (2004), no. 1, 266-278.

[8] - The equivalence of Mann iteration and Ishikawa iteration for a Lipschitzian $\psi$-uniformly pseudocontractive and $\psi$-uniformly accretive maps, Tamkang Journal of Mathematics 35 (2004), no. 3, 235-245. 
[9] Ş. M. Şoltuz, The equivalence of Picard, Mann and Ishikawa iterations dealing with quasi-contractive operators, Mathematical Communications 10 (2005), no. 1, 81-88.

[10] X. Weng, Fixed point iteration for local strictly pseudo-contractive mapping, Proceedings of the American Mathematical Society 113 (1991), no. 3, 727-731.

B. E. Rhoades: Department of Mathematics, Indiana University, Bloomington, IN 47405-7106, USA E-mail address: rhoades@indiana.edu

Ştefan M. Şoltuz: “Tiberiu Popoviciu” Institute of Numerical Analysis, Romanian Academy, Tiberiu Popoviciu, P.O. Box 68-1, 400110 Cluj-Napoca, Romania

E-mail addresses: smsoltuz@gmail.com; soltuzul@yahoo.com 


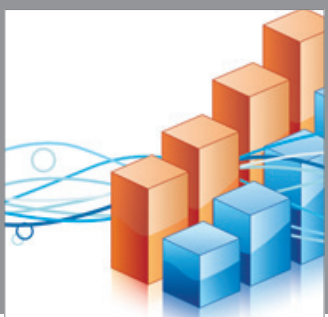

Advances in

Operations Research

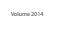

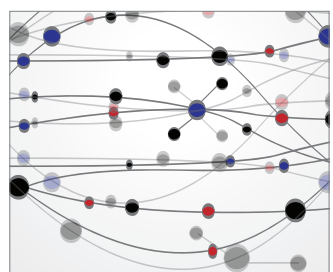

\section{The Scientific} World Journal
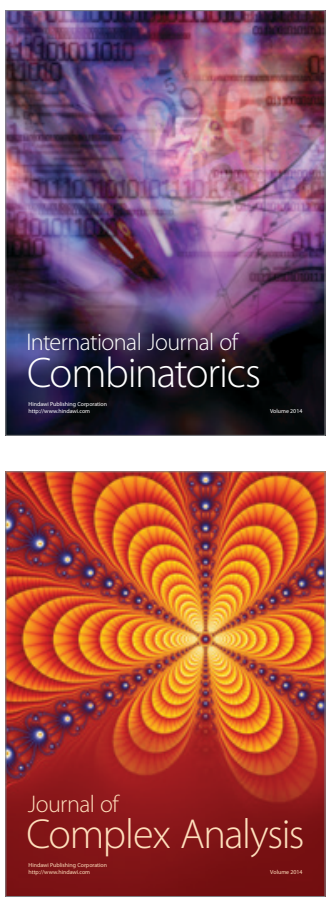

International Journal of

Mathematics and

Mathematical

Sciences
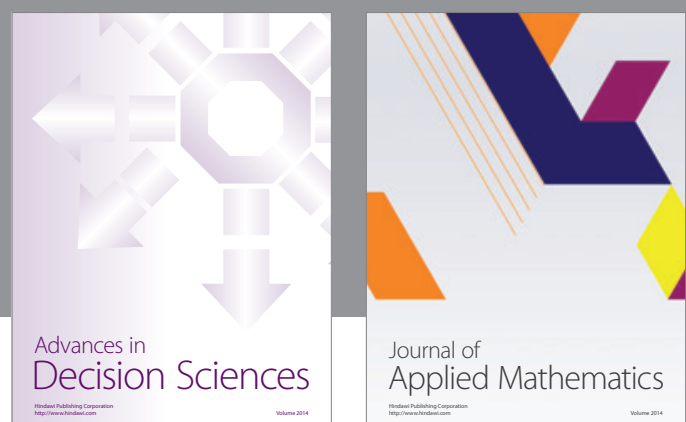

Journal of

Applied Mathematics
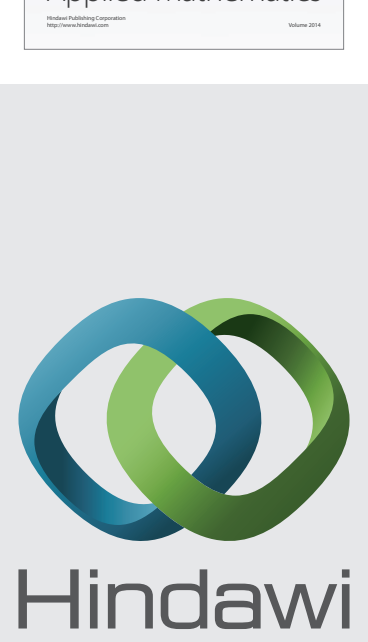

Submit your manuscripts at http://www.hindawi.com
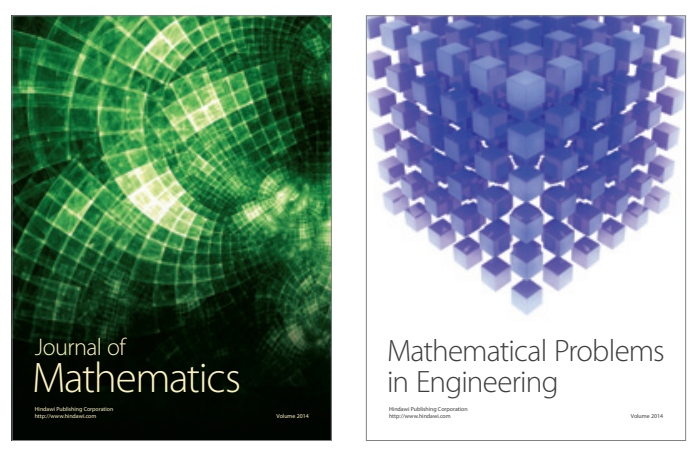

Mathematical Problems in Engineering
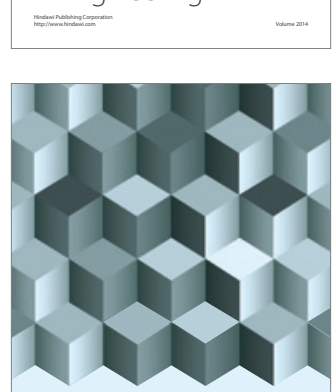

Journal of

Function Spaces
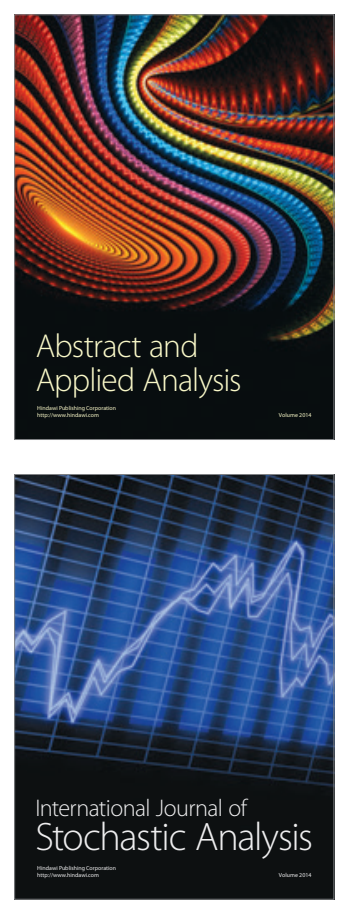

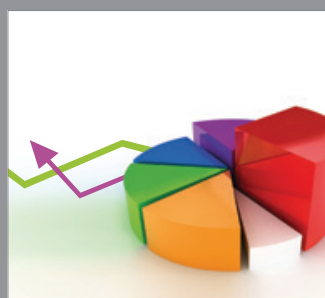

ournal of

Probability and Statistics

Promensencen
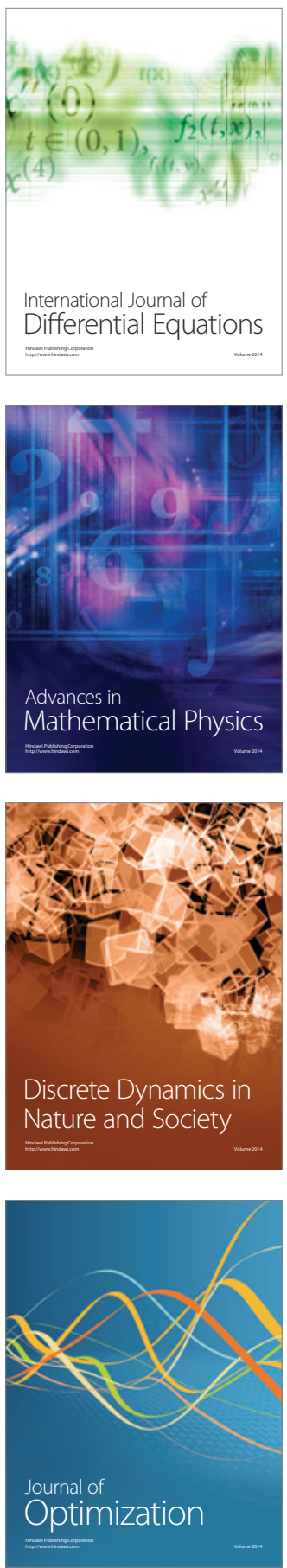